\title{
The Outcomes of Intravitreal C3F8 Gas Tamponade Combined with Laser Photocoagulation Treatment for Optic Disc Pit Maculopathy
}

\author{
Deniz Mirza ( $\sim$ gayretli.deniz@gmail.com ) \\ Necmettin Erbakan Universitesi Meram Tip Fakultesi https://orcid.org/0000-0002-3073-1213 \\ Enver Mirza \\ Necmettin Erbakan University Meram Faculty of Medicine: Necmettin Erbakan Universitesi Meram Tip Fakultesi \\ Gunhal Satirtav \\ Necmettin Erbakan University Meram Faculty of Medicine: Necmettin Erbakan Universitesi Meram Tip Fakultesi \\ Hurkan Kerimoglu \\ Necmettin Erbakan University Meram Faculty of Medicine: Necmettin Erbakan Universitesi Meram Tip Fakultesi
}

\section{Research Article}

Keywords: Optic disc pit, optic disc pit maculopathy, C3F8gas tamponade, laser photocoagulation

Posted Date: August 30th, 2021

DOI: https://doi.org/10.21203/rs.3.rs-713970/v1

License: (c) (i) This work is licensed under a Creative Commons Attribution 4.0 International License. Read Full License

Version of Record: A version of this preprint was published at International Ophthalmology on January 28th, 2022. See the published version at https://doi.org/10.1007/s10792-021-02179-0. 


\section{Abstract}

Purpose: To share the anatomical results and visual outcomes of intravitreal gas tamponade combined with laser photocoagulation treatment for optic disc pit maculopathy (ODPM).

Methods: Intravitreal gas tamponade combined with laser photocoagulation treatmentwas performed on six consecutive patients with ODPM. A $0.3-\mathrm{mL}$ of $100 \%$ octafluoropropane (C3F8) gas was injected intravitreally. The patients were then asked to maintain prone position until the $\mathrm{C}_{3} \mathrm{~F}_{8}$ gas disappeared. Laser photocoagulation was performed the day after the procedure. The outcomes were determined by spectral-domain optical coherence tomography and best-corrected visual acuity (BCVA).

Results: In the present study, visual improvement and reduction in serous macular detachment was observed in $83 \%$ of the ODPM patients. Complete retinal reattachment was achieved in $66 \%$ of the ODPM patients. In one patient, no regression was observed after the repeated treatment and pars plana vitrectomy was performed. The final BCVA improved in five eyes and unchanged in one eye. No postoperative complications were observed during the follow-up period in any patient.

Conclusions: Intravitreal C3F8 gas tamponade combined with laser photocoagulation procedure is an effective, minimally invasive, and cost-effective treatment method for ODPM.

\section{Introduction}

Optic disc pit (ODP), which was first described by Wiethe in 1882 [2], is a congenital cavitary anomaly of the optic disc [1]. It is a rare condition with an estimated prevalence of 1 in 11.000 patients [3]. ODP is typically seen as unilateral, oval-shaped, graywhite depression and most commonly located in the temporal portion of the optic disc [4].

ODP is generally asymptomatic but serous macular detachment develops in $25-75 \%$ of patients which is termed as ODP maculopathy (ODPM) [5]. Visual deterioration or vision loss is the most common initial complaint of the patients. ODPM may occur during childhood but it is most common between second and fourth decades of life [6]. The pathogenesis of ODPM remains unclear but there are several hypotheses including liquefied vitreous entering through the ODP, cerebrospinal fluid entering from the subarachnoid space through the ODP, and leakage from blood vessels at the ODP or the choroid about the origin of fluid seen in the intraretinal and subretinal spaces in the literature [7].

It is known that the prognosis is poor if ODPM patients are left untreated [6]. On the other hand, there is no accepted standard treatment method for ODPM, to date. Pars plana vitrectomy (PPV) is the most commonly used surgical procedure for the treatment of ODPM especially in patients with vitreomacular or vitreopapillary traction [7]. Different surgical techniques such as the inverted internal limiting membran-flap, macular buckling, retinal fenestration, glial tissue removal, and autologous fibrin were also combined with PPV but the reports evaluating these treatment modalities were limited by small sample sizes and some serious complications have been reported [8-12].

In the previous studies, alternative treatment procedures such as laser photocoagulation alone or intravitreal gas tamponade alone has been performed in patients with ODPM [13-15]. But the results were not promising. Intravitreal gas tamponade combined with prone position and laser photocoagulation treatment has better results and this procedure may be an alternative to surgery $[16,17]$.

On this basis, the aim of the present study is to share the anatomical results and visual outcomes of six patients who underwent intravitreal C3F8 gas tamponade combined with prone position and laser photocoagulation treatment procedure for the ODPM.

\section{Materials And Methods}

The file records of six patients with OPDM who were treated and followed-up between January 2013 and June 2020 in the Necmettin Erbakan University, Meram School of Medicine Hospital, Department of Ophthalmology were reviewed. 
All patients underwent detailed ophthalmologic examination preoperatively and postoperatively in every visit. Best-corrected visual acuity (BCVA) was recorded. Intraocular pressure was measured by Goldmann applanation tonometry. Anterior segment was evaluated with slit-lamp biomicroscopy. Funduscopic examination was performed after pupillary dilatation. Color fundus photography (TRC-50IX; Topcon, Tokyo, Japan) of the posterior segment was taken. Spectral-domain optical coherence tomography (SD-OCT; Heidelberg Engineering, Heidelberg, Germany) was performed.

Primarily, PPV were suggested to the patients for the treatment of ODPM and those who did not accept surgery received intravitreal gas tamponade combined with prone position and laser photocoagulation. All treatment procedures were performed by the same vitreoretinal surgeon (HK). The intravitreal C3F8 gas tamponade was performed under topical anesthesia.

Paracentesis from the anterior chamber and discharge of $0.1-0.2 \mathrm{ml}$ aqueous humor was followed by injection of $0.3 \mathrm{ml}$ of $100 \%$ octafluoropropane gas $\left(\mathrm{C}_{3} \mathrm{~F}_{8}\right)$ into the vitreous cavity using a 30-gauge needle. The patients were asked to maintain prone position for at least one week, and as much as possible in the following days until the gas bubble disappears. Laser photocoagulation was performed the day after gas injection. Two to three rows of laser burns were placed to the temporal border of the ODP with a spot size of $100 \mu \mathrm{m}$. Exposures of $0.1 \mathrm{~s}$ were used and the power adjusted aiming a mild gray burn at the level of the retinal pigment epithelium.

After the treatment procedure all patients were examined and SD-OCT was performed at weekly intervals for 1 month, at 3month intervals for 1 year, and every 6 months thereafter. The same treatment procedure was repeated if serous macular detachment or retinoschisis still existed or progressed during the follow-up.

\section{Results}

\section{Clinical characteristics}

This retrospective study included 6 eyes of 3 male and 3 female patients. The mean age of patients was 37.1 years (ranged 1466 years). The clinical characteristics of the six patients are demonstrated in Table 1. Fundus photographs of representative patients are shown in Figs. 1a and 2a. Five patients presented with decreased vision and/or metamorphopsia in the affected eye, one patient was diagnosed incidentally (Patient 3). The patient 5 had high myopia (>6D), while the other patients had no significant refractive error. Vitreomacular or vitreopapillary traction was not detected in SD-OCT scans at the initial examination in any patient (Fig. $1 \mathrm{~b}$ and $2 \mathrm{~b}$ ). 
Table 1

Clinical Characterestics of the Patients with ODPM

\begin{tabular}{|c|c|c|c|c|c|c|c|c|c|c|}
\hline Patient & Age & Eye & Gender & $\begin{array}{l}\text { Duration } \\
\text { of } \\
\text { Semptom }\end{array}$ & $\begin{array}{l}\text { Initial } \\
\text { BCVA }\end{array}$ & $\begin{array}{l}\text { Final } \\
\text { Retinal } \\
\text { Results }\end{array}$ & $\begin{array}{l}\text { Duration } \\
\text { until } \\
\text { macular } \\
\text { attachment } \\
\text { (months) }\end{array}$ & $\begin{array}{l}\text { Final } \\
\text { BCVA }\end{array}$ & $\begin{array}{l}\text { Follow- } \\
\text { up } \\
\text { (months) }\end{array}$ & $\begin{array}{l}\text { Additional } \\
\text { Treatment }\end{array}$ \\
\hline 1 & 48 & $\mathrm{R}$ & $M$ & 3 months & $20 / 200$ & Reattached & 12 & $20 / 50$ & 15 & No \\
\hline 2 & 14 & $\mathrm{~L}$ & $M$ & 1 month & $20 / 63$ & Reattached & 18 & $20 / 32$ & 32 & No \\
\hline 3 & 66 & $\mathrm{R}$ & $\mathrm{F}$ & Unknown & $20 / 400$ & $\begin{array}{l}\text { No } \\
\text { improvement }\end{array}$ & $\mathrm{N} / \mathrm{A}$ & $20 / 400$ & 24 & $\begin{array}{l}\text { Repeated } \\
\text { treatment } \\
+ \text { PPV }\end{array}$ \\
\hline 4 & 18 & $\mathrm{~L}$ & $\mathrm{~F}$ & 7 months & $20 / 32$ & Reattached & 10 & $20 / 20$ & 24 & No \\
\hline 5 & 51 & L & $F$ & 1 month & $20 / 50$ & Reattached & 1 & $20 / 32$ & 4 & $\begin{array}{l}\text { Repeated } \\
\text { treatment }\end{array}$ \\
\hline 6 & 25 & $\mathrm{~L}$ & $M$ & 2 weeks & $2 \mathrm{mfc}$ & Flattened & $\mathrm{N} / \mathrm{A}$ & $20 / 40$ & 4 - LTF & No \\
\hline
\end{tabular}

\section{Anatomic results}

Complete retinal reattachment was achieved in 4 out of 6 eyes (Patients 1, 2, 4, and 5) (Figs. 1c and 2c). Among these 4 eyes, repeated treatment was required only in one patient (Patient 5). Reduction of the inner retinal layer schisis and outer retinal layer detachment was observed immediately after the treatment procedure. Complete fluid absorption was achieved after a mean of 10.3 months (range 1-18 months). Complete retinal reattachment was not achieved in patient 3 and patient 6 . Patient 6 showed a significant decrease in serous macular detachment and retinoschisis with improved BCVA (Fig. 3a and 3b). However, he did not come to follow-up after the 4th month visit. The patient was communicated by phone due to restricted circumstances in the COVID-19 pandemic and had no complaints regarding the procedure. Patient 3 showed a decrease in serous macular detachment in the first month visit. However, it was observed that the fluid increased again and there was no improvement in BCVA in the follow-up visits. Despite repeated treatment, no improvement was observed in the subsequent follow-ups and PPV surgery was performed.

We should emphasize that none of four treated patients showed any recurrence after the complete retinal reattachment during the follow-up periods. The mean follow-up time of the patients, whose subretinal fluid was reabsorbed, was 17.1 months (ranged 4-32 months). No intraoperative or postoperative complications were observed in any patients.

\section{Visual acuity results}

Preoperative and the final BCVA values are shown in Table 1. The final BCVA improved in five eyes and unchanged in one eye. The mean BCVA values of the patients, which was 20/160 preoperatively, increased to 20/50 at the last examination.

\section{Discussion}

ODPM is a rare disease and its pathogenesis is not entirely clear. The management of ODPM is still challenging for the vitreoretinal surgeons. Since significant visual loss was observed in the majority of untreated cases, numerous treatment methods have been applied for the ODPM [6]. None of them have been identified as the gold standard treatment. Nowadays, the predominant approach for ODPM management is PPV especially in patients with vitreomacular traction [7]. Several authors have reported the results of PPV, in combination with gas tamponade, endolaser photocoagulation, silicone oil tamponade, internal limiting membrane (ILM) peeling or subretinal fluid drainage [18-22]. These studies have shown that PPV gives very 
encouraging long-term anatomical, functional outcomes and patients have satisfactory postoperative visual acuity results [18, 21, 23]. Nevertheless, the potential complications of PPV, including cataracts, retinal tear and retinal detachment, should be taken into consideration $[24,25]$.

Recently, in the meta-analysis of Zheng et al, six different surgical procedures including PPV alone, PPV with laser photocoagulation, PPV with ILM peeling, PPV with both ILM peeling and laser photocoagulation, PPV with inner retinal fenestration, and PPV with autologous platelet concentrate have been evaluated in the treatment of patients with ODPM [26]. The authors have investigated visual acuity changes, serous macular reattachment rate, reattachment time and macular thickness changes by OCT and it was reported that they have not found any significant difference in functional outcomes among these six surgical procedures.

Intravitreal gas tamponade facilitates dissection of the posterior hyaloid. The prone position allows subretinal fluid to be absorbed and the retinal pigment epithelium to attach to the sensory retina. Akiyama et al. used intravitreal gas tamponade alone in patients with ODPM [27]. They reported that, only 4 out of 8 eyes had achieved complete resolution of intra-subretinal fluids. Also, repeated intravitreal gas injection was performed in 3 of these 4 eyes. Laser photocoagulation alone was also used for the treatment in patients with ODPM but the results were not very promising $[28,29]$. In addition to the intravitreal gas tamponade treatment, laser photocoagulation can block the abnormal junction between ODP and adjacent subretinal space. When they are applied together, the gas also keeps neural retina and pigment epithelium in contact near the optic nerve head to allow the laser spots to create adhesion. Therefore, it plays a critical role in reducing fluid flow from ODP to macular region [16].

Lei et al. reported that they achieved complete retinal reattachment in 7 out of 9 eyes with intravitreal C3F8 tamponade combined with laser photocoagulation. Repeated treatment was required in 3 of these eyes. In addition, visual improvement and significant fluid decrease were observed in the other 2 eyes [16]. Elmohamady et al. also applied intravitreal sulphur hexafluoride $\left(\mathrm{SF}_{6}\right)$ gas tamponade combined with laser photocoagulation in patients with ODPM. They reported that the treatment resulted in complete resolution of subretinal fluid in all of the patients. Repeated injections were required in 2 of the 11 eyes. In addition, they observed no recurrence in any of the patients during the follow-up period [17].

In the present study, after the intravitreal $\mathrm{C}_{3} \mathrm{~F}_{8}$ gas tamponade combined with prone position and laser photocoagulation treatment procedure, complete retinal reattachment was achieved in 4 of 6 patients. Furthermore, serous macular detachment and retinoschisis-like changes decreased in 5 of 6 patients. Patient 6 showed a significant decrease in the serous macular detachment and his BCVA improved within 4 months of follow-up. As reported previously, a long follow-up period may be required to achieve complete retinal reattachment in some patients with ODPM. It has been observed that complete retinal attachment may take up to 18 months [16]. When the follow-up time is extended in patient 6 , more acceptable treatment results are likely to be achieved.

In patient 3, because no regression was observed after the second intravitreal gas tamponade injection, PPV was performed. The reason for the failure of the technique in this patient may depend on two factors. Firstly, the age of the patient might have affected the success considering that the patient 3 was the oldest patient (age; 66) in our case series. It has been demonstrated that younger patients may have a higher chance of success in our treatment procedure [17]. She presented with asthenopic complaints and the diagnosis was made incidentally. She did not recognize the vision loss in her eye. Probably, serous macular detachment and retinoschisis-like changes had been present for a long time. Lee et al. have supported that the delayed treatment is associated with poor anatomic and functional outcomes [16].

We have informed our patients about the benefits and complications of PPV and intravitreal gas tamponade combined with laser photocoagulation treatment procedure. In our cases, ODPM patients have preferred this procedure before PPV due to it is less invasive and has a relatively low complication rate. They have chosen PPV to be performed in the second stage in case of failure. The choice of secondary PPV can be considered reasonable because almost all of our patients did not have vitreomacular or vitreopapillary traction. However, PPV surgery was performed in one patient because no improvement was observed despite repeated treatment. Since ODPM is a rare disease, it is difficult to conduct a randomized controlled trial with a large case series. Nevertheless, the results of our study show that the anatomical and visual results of intravitreal C3F8gas 
tamponade combined with laser photocoagulation treatment are encouraging and this procedure can be performed under topical anesthesia confidently.

\section{Conclusion}

In the present study, we observed improvement in BCVA values and regression in serous macular detachment in $83 \%$ of the ODPM patients. Complete retinal reattachment was achieved in $66 \%$ of the ODPM patients. While making the treatment procedure decision, patient expectations should be taken into consideration. Intravitreal gas tamponade combined with prone position and laser photocoagulation procedure has a high rate of success and can be planned as an alternative treatment or can be recommended to ODPM patients before PPV.

\section{Declarations}

Funding: There is no funding

Conflicts of interest: The authors declare that they have no conflict of interest

Ethics approval: The present study was approved by the Ethical Committee of Necmettin Erbakan University and adhered to the tenets of the Declaration of Helsinki (No.:2020/2621)

Consent to participate: Not applicable

Consent for publication: Not applicable

Availability of data and material: The datasets analyzed during the current study are available from the corresponding author on reasonable request.

Code availability: Not applicable

\section{References}

1. Jain N, Johnson MW (2014) Pathogenesis and treatment of maculopathy associated withcavitary optic disc anomalies. Am $\mathrm{J}$ Ophthalmol 158:423-435

2. Wiethe T (1882) Ein fall von angeborener deformität der sehnervenpapille. Arch Augenheilkd 11:14-19

3. Reis W (1908) Ein wenig bekannte typische Missbildung am Sehnerveneintritt. Z Augenheilk 19:505-528

4. Theodossiadis PG, Grigoropoulos VG, Emfietzoglou J, Theodossiadis GP (2007) Vitreous findings in optic disc pit maculopathy based on optical coherence tomography. Graefes Arch Clin Exp Ophthalmol 245(9):1311-1318

5. Bonnet M (1991) Serous macular detachment associated with optic nerve pits. Graefes Arch Clin Exp Ophthalmol 229(6):526-532

6. Sobol WM, Blodi CF, Folk JC, Wein-geist TA (1997) Long-term visual out- come in patients with optic nerve pit and serous retinal detachment of the macula. Ophthalmology 11:1539-1542

7. Moisseiev E, Moisseiev J, Loewenstein A (2015) Optic disc pit maculopathy: when and how to treat? A review of the pathogenesis and treatment options. Int J Retina Vitreous. https://doi.org/10.1186/s40942-015-0013-8

8. Sborgia G, Recchimurzo N, Sborgia L, Niro A, Sborgia A, Piepoli M, Alessio G (2021) Inverted Internal Limiting MembraneFlap Technique For Optic Disk Pit Maculopathy: Morphologic And Functional Analysis. Retin Cases Brief Rep 15(1)(1):3137. doi 10.1097/ICB.0000000000000731.

9. Georgopoulos GT, Theodossiadis PG, Kollia AC, Vergados J, Patsea EE, Theodossiadis GP (1999) Visual field improvement after treatment of optic disk pit maculopathy with the macular buckling procedure. Retina 19:370-377.

https://doi.org/10.1097/00006982-199909000-00001

Page $6 / 9$ 
10. Ooto S, Mittra RA, Ridley ME, Spaide RF (2014) Vitrectomy with inner retinal fenestration for optic disc pit maculopathy. Ophthalmology 121:1727-1733. https://doi.org/10.1016/j.ophtha.2014.04.006

11. Inoue M, Shinoda K, Ishida S (2008) Vitrectomy combined with glial tissue removal at the optic pit in a patient with optic disc pit maculopathy: A case report. J Med Case Rep 2:103

12. Ozdek S, Ozdemir HB (2017) A new technique with autologous fibrin for the treatment of persistent optic pit maculopathy. Retin Cases Brief Rep 11:75-78

13. Mustonen E, Varonen T (1972) Congenital pit of the optic nerve head associated with serous detachment of the macula. Acta ophthalmologica 50(5):689-698. https://doi.org/10.1111/j.1755-3768.1972.tb06609.x

14. Theodossiadis $\mathrm{G}$ (1988) Treatment of retinal detachment with congenital optic pit by krypton laser photocoagulation. Graefes Arch Clin Exp Ophthalmol 226(3):299

15. Lincoff H, Kreissig I (1998) Optical coherence tomography of pneumatic displacement of optic disc pit maculopathy. Br J Ophthalmol 82(4):367-372

16. Lei L, Li T, Ding X, Ma W, Zhu X, Atik A, Hu Y, Tang S (2015) Gas tamponade combined with laser photocoagulation therapy for congenital optic disc pit maculopathy. Eye (Lond 29(1):106-114. doi:10.1038/eye.2014.245

17. Elmohamady MN, Khalil MTI, Bayoumy ASM, Rateb M, Faramawi HM (2020) Sulphur hexafluoride (SF6) intravitreal injection combined with argon laser photocoagulation for treatment of optic disc pit maculopathy. Eye (Lond). doi:10.1038/s41433-020-0867-3

18. Garcia-Arumi J, Guraya BC, Espax AB, Castillo VM, Ramsay LS, Motta RM (2004) Optical coherence tomography in optic pit maculopathy managed with vitrectomy-laser-gas. Graefes Arch Clin Exp Ophthalmol 242(10):819-826

19. Shukla D, Kalliath J, Tandon M, Vijayakumar B (2012) Vitrectomy for optic disk pit with macular schisis and outer retinal dehiscence. Retina 32(7):1337-1342

20. Johnson TM, Johnson MW (2004) Pathogenic implications of subretinal gas migration through pits and atypical colobomas of the optic nerve. Arch Ophthalmol 122(12):1793-1800

21. Georgalas I, Petrou P, Koutsandrea C, Papaconstadinou D, Ladas I, Gotzaridis E (2009) Optic disc pit maculopathy treated with vitrectomy, internal limiting membrane peeling, and gas tamponade: a report of two cases. Eur J Ophthalmol 19(2):324-326

22. Schaal KB, Wrede J, Dithmar S (2007) Internal drainage in optic pit maculopathy. Br J Ophthalmol 91(8):1093

23. Talli PM, Fantaguzzi PM, Bendo E, Pazzaglia A (2016) Vitrectomy without laser treatment for macular serous detachment associated with optic disc pit: long-term outcomes. Eur J Ophthalmol 26(2):182-187

24. Avci R, Kapran Z, Ozdek Ş, Teke MY, Oz O, Guven D, Yilmaz S, Kaderli B, Durukan AH, Sobaci G, Unver YB, Akduman L, Kaynak S, Dogan I, Inan UU (2017) Multicenter study of pars plana vitrectomy for optic disc pit maculopathy: MACPIT study. Eye (Lond)(9):1266-1273. doi:10.1038/eye.2017.142

25. Bottoni F, Cereda M, Secondi R, Bochicchio S, Staurenghi G (2018) Vitrectomy for optic disc pit maculopathy: a long-term follow-up study. Graefes Arch Clin Exp Ophthalmol 256(4):675-682. doi:10.1007/s00417-018-3925-9

26. Zheng A, Singh RP, Lavine JA (2020) Surgical Options and Outcomes in the Treatment of Optic Pit Maculopathy: A Metaanalysis and Systematic Review. Ophthalmol Retina 4(3):289-299. doi:10.1016/j.oret.2019.10.011

27. Akiyama H, Shimoda Y, Fukuchi M, Kashima T, Mayuzumi H, Shinohara Y, Kishi S (2014) Intravitreal gas injection without vitrectomy for macular detachment associated with an optic disk pit. Retina34(2):222-7. doi: 10.1097/IAE.0b013e3182993d93

28. Cox MS, Witherspoon CD, Morris RE, Flynn HW (1998) Evolving techniques in the treatment of macular detachment caused by optic nerve pits, 95 . Ophthalmology, pp 889-896

29. Schatz H, McDonald HR (1988) Treatment of sensory retinal detachment associated with optic nerve pit or coloboma. Ophthalmology 95:178-186

\section{Figures}




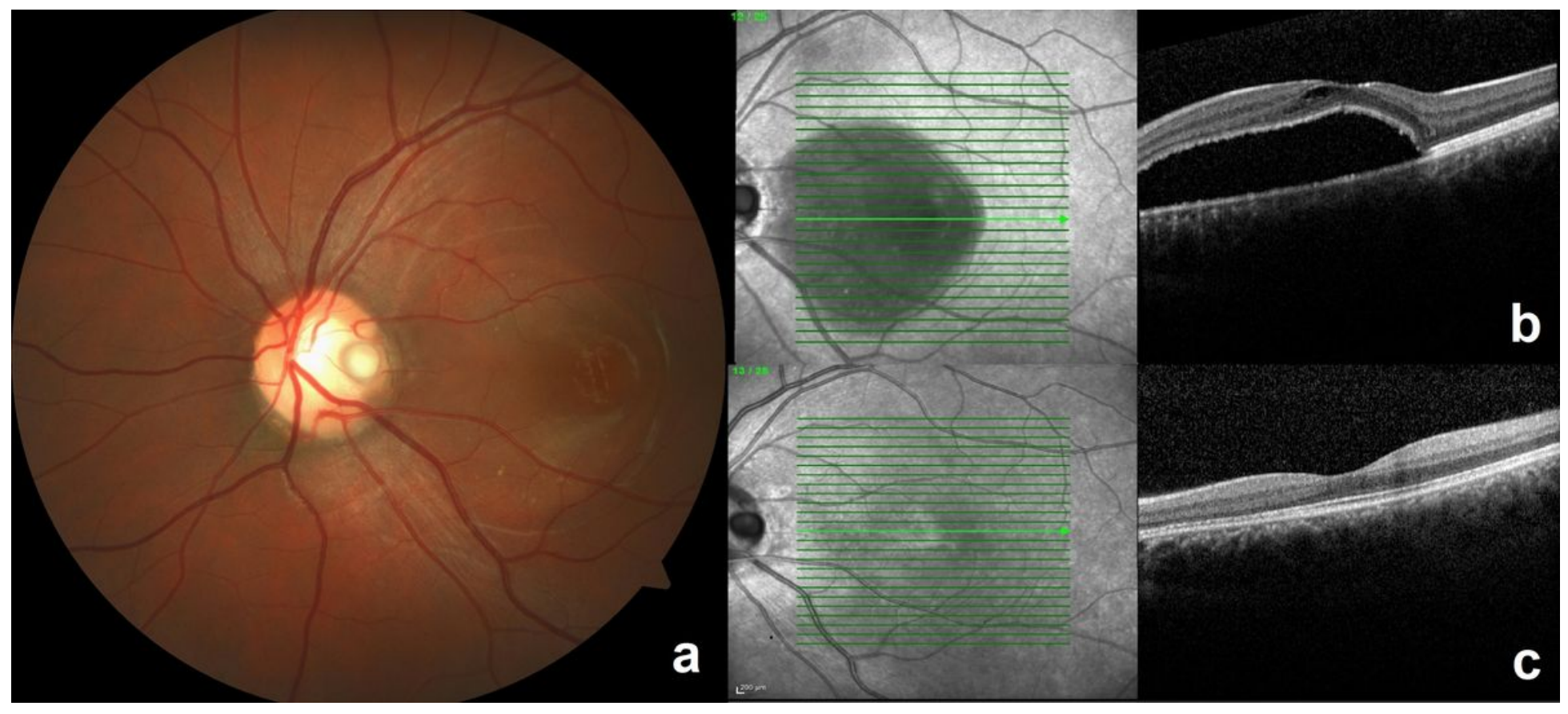

Figure 1

1a. The fundus photograph of patient 4 before the treatment showing optic disc pit and serous macular detachment $1 \mathrm{~b}$. OCT image of the same patientbefore the treatment showing subretinal fluid 1c. OCT image of the same patientafter the treatment showing retinal reattachment.

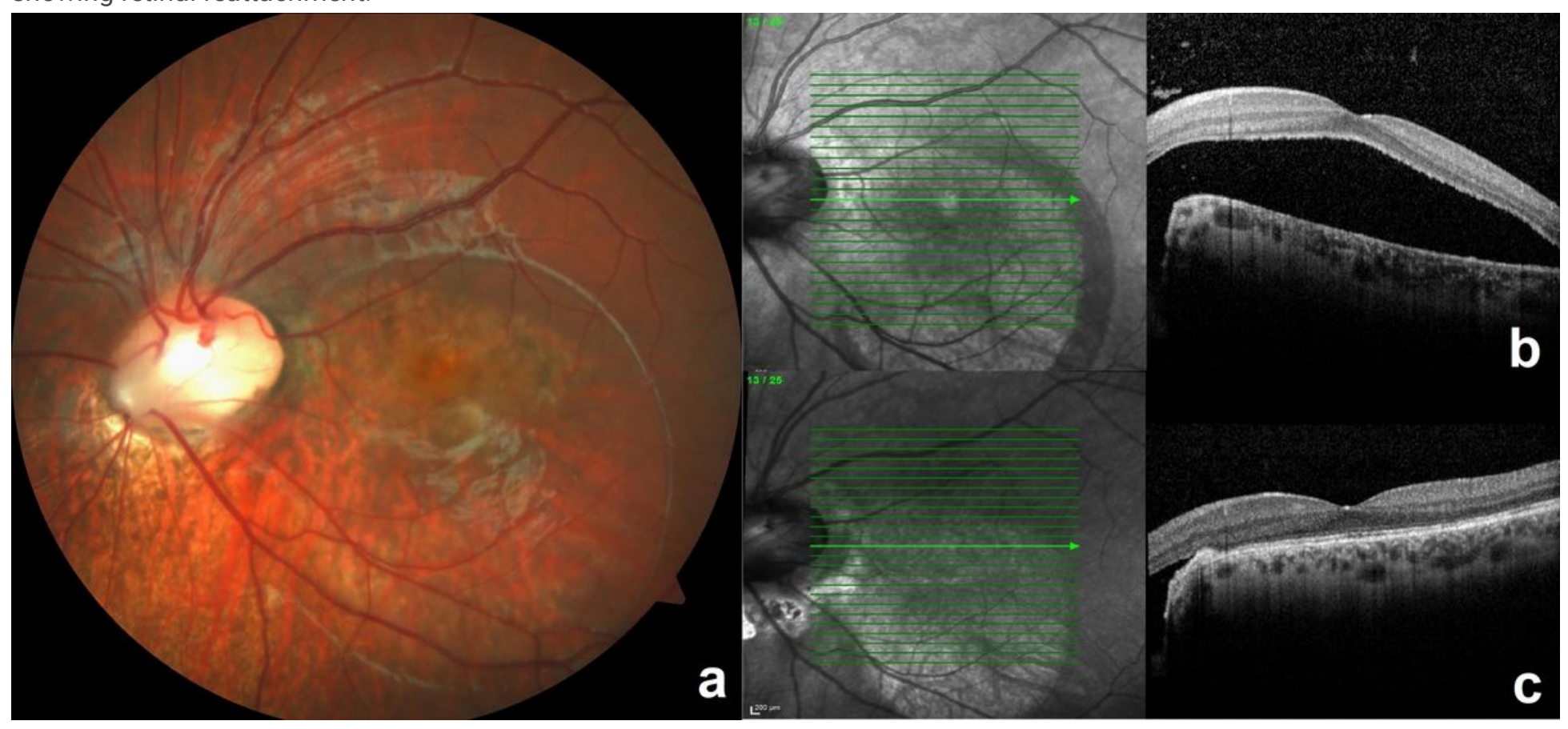

\section{Figure 2}

2a. The fundus photograph of patient 2 before the treatment showing optic disc pit and serous macular detachment $2 \mathrm{~b}$. OCT image of the same patientbefore the treatment showing subretinal fluid 2c. OCT image of the same patientafter the treatment showing retinal reattachment. 


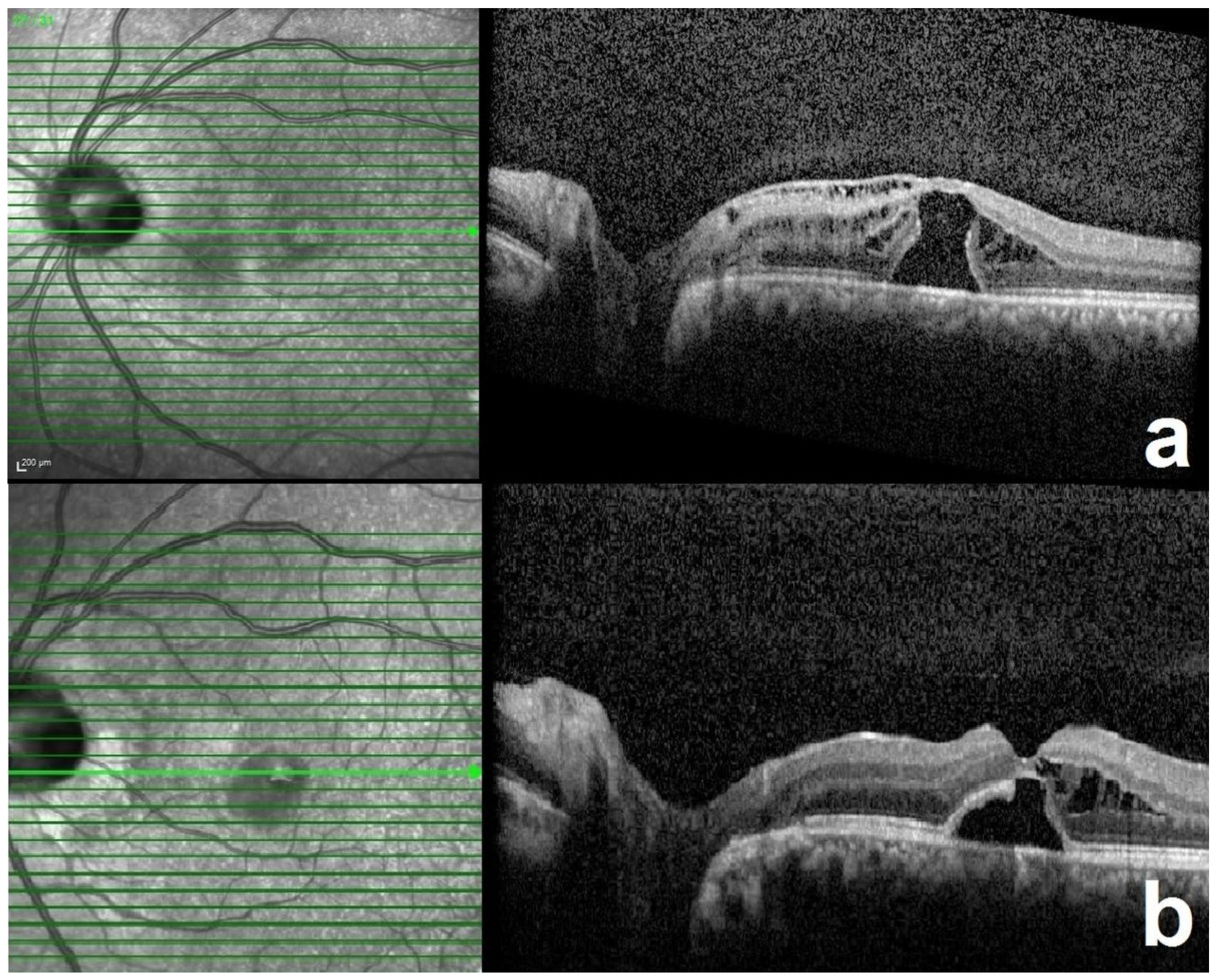

\section{Figure 3}

3a. OCT image of patient 6before the treatment showing serous macular detachment and retinoschisis $3 \mathrm{~b}$. OCT image of the same patient after the treatment showing decrease in serous macular detachment and retinoschisis. 